\title{
The Structure of Content is Not Transparent
}

\author{
Thomas Hodgson ${ }^{1}[\mathbb{D}$
}

Published online: 14 November 2017

(c) The Author(s) 2017. This article is an open access publication

\begin{abstract}
Sentences in context have semantic contents determined by a range of factors both internal and external to speakers. I argue against the thesis that semantic content is transparent to speakers in the sense of being immediately accessible to speakers in virtue of their linguistic competence.
\end{abstract}

Keywords Content · Externalism · Propositions · Russellianism

\section{Introduction}

When a sentence is uttered it has a semantic content relative to the context of its utterance. The semantic content is fixed by (i) the contents of the simple expressions in the sentence as fixed by what we call metasemantics, (ii) the way contents of simple expressions interact in sentences, and (iii) the context. Let's assume this picture, and the additional claim that semantic contents are structured, Russellian propositions. ${ }^{1}$

The question I am considering in this paper is: how much do speakers know, tacitly or otherwise, about the semantic contents of the sentence that they utter, in virtue of their being competent language users? I will assume that most speakers are competent most of the time, and I will call their broadest competence linguistic competence and, where content is specifically at issue rather than e.g. syntax I will refer to semantic competence. This is a complicated question with many facets. I will focus on a small, tractable sub-question.

I will argue that there are reasons to reject the thesis that speakers have a particular sort of knowledge of semantic content. I will call that thesis transparency in what follows; I will define it more precisely in Sects. 2 and 3.

Thomas Hodgson

hello@twshodgson.net

1 School of Philosophy, University College Dublin, Dublin, Ireland

\section{The Transparency Intuition}

I will approach the question of transparency via a discussion in a recent paper of Imogen Dickie's (2014). The topic of Dickie's paper is how to give a satisfactory account of 'empty' singular thought. This problem arises in a particular philosophical tradition that I am also working in. On this view, thinking a singular thought is a matter of standing in a certain relation to a particular sort of singular content. These are singular propositions which contain objects. If there is no object, then, presumably, there is no suitable singular proposition and therefore no singular thought. Dickie presents this as a problem for thought, specifically for the claim that some thoughts can be justified when they are both (i) intuitively identified as singular and (ii) lack a suitable singular propositional content. A related issue arises for the semantic contents of sentences that would standardly be assigned singular propositions as contents. This is the version of the problem I am interested in.

Dickie considers several ways to solve this problem. Her preferred solution is that a thought can count as singular, and be justified, even in the absence of a suitable proposition. The equivalent idea at the sentence level would be to say that sentences containing empty singular terms do not have semantic contents. My concern in this paper is not with Dickie's positive view. Instead, I am interested in something she says about an alternative view that she rejects. The alternative view is that when a singular term is empty the thought has a content but that content is not a singular proposition: it

\footnotetext{
${ }^{1}$ I am therefore working within the framework that contemporary
} philosophers have developed from the work of Russell (1903). 
is a general proposition such as those that are the semantic contents of sentences containing quantifiers. Dickie writes:

[Y]ou can detect no difference between the structure of your thoughts in the 'good' cases (where your thoughts are about objects) and the 'bad' cases (where, unbeknownst to you, aboutness fails). But, on the face of things, if there is a difference in structure between thoughts, this is a difference detectable by the subject. So, since you can detect no structural difference between the cases, there is no such difference. And if there is no structural difference between 'good' thoughts and 'bad' ones, it cannot be that 'bad' thoughts are descriptive and 'good' thoughts not (Dickie 2014, p. 217).

I think that it is reasonable to read 'thoughts' here as meaning propositions i.e. the contents of thoughts and the things that are semantic contents. And I think that Dickie's idea can be transposed to the question of whether the semantic contents of sentences can be singular in good cases and general in bad cases. I will also proceed on the assumption that Dickie's argument is supposed to be a contribution to the question about semantic content I identified in Sect. 1; if not, then my argument is less relevant to her's. ${ }^{2}$ However, I think that my argument is still interesting in the context of my own project. I will formulate the idea extracted from Dickie's discussion and applied to semantic content as transparency of structure. ${ }^{3}$

Transparency of Structure If there is a difference in structure between the semantic contents of sentences, this is a difference detectable by the utterers of these sentences.

I will assume that what 'detectable' means in the current context relates to some kind of immediate access that utterers might have to facts about content. In other words, a difference in structure need not be detected all the time in order to be transparent if conditions for exercising semantic competence are not ideal. But a difference does not count as detectable if it can only be discerned by making empirical investigations that are not required to be ordinarily competent with the sentence in question. Structure being detectable requires knowledge, tacit or otherwise, of the structural difference in question if the utterer is semantically competent with the sentence and the conditions for exercising that

\footnotetext{
2 One way in which someone might have a different view of the debate here is that they might think that the important issue is what proposition a speaker conveyed i.e. speech-act content as opposed to semantic content. I find transparency more plausible there. But in any case I am interested in this paper just in semantic content. I thank Elmar Geir Unnsteinsson for discussion of this point

3 The term transparency is also used in Schroeter (2007) to refer to a related idea closest to what I will call transparency of content in Sect. 3.1. As will become clear, my position is compatible with Laura Schroeter's.
}

competence fully are met. The differences in structure I am concerned with are just those that Dickie's discussion focused on: the difference between a singular proposition and a general one.

In the rest of this paper I will consider the kind of transparency that is at issue to be the possibility that some particular sort of fact about content is available to speakers, through introspection, as a result of their linguistic competence. That speakers have this ability is what I will deny. And, if they do not, the argument Dickie gives will not go through. I have chosen to present transparency in this way, because I take it to be what would support Dickie's argument if it were true. This is because the argument relies on the premise that if the content was singular in one case and general in another the respective speakers would know that the structure is different.

Dickie's argument relies on transparency, specifically what I call transparency of structure. And, in her argument transparency of structure is supported by an appeal to what I will call the transparency intuition which is just the judgement that transparency of structure is true. I am interested in whether transparency in general is true; I will discuss several versions in this paper.

I don't think that the transparency intuition is decisive evidence even if it is in fact widespread. Transparency is clearly a coherent, interesting thesis independently of the transparency intuition. So, a better strategy for assessing it is to consider philosophical arguments for and against it.

\section{Varieties of Transparency}

\subsection{Content and Structure}

The claim presented in Sect. 2 is about transparency of structure: speakers know something about the structure of the semantic contents of the sentences that they utter. In particular, whether that content is singular or general. A content is singular if it is about an object (or objects) which are among its constituents; otherwise it is general, which just means nonsingular. In other words, transparency as defined above requires knowing something about the semantic content of a sentence. ${ }^{4}$ But it does not require knowing what that content

\footnotetext{
${ }^{4}$ I will speak in terms of knowledge, but, as an anonymous referee pointed out, there may well be cases where justified belief is sufficient. Everything I say could be put in such terms.
} 
is, nor does it require knowing exactly what that structure is because there are a variety of singular and general structures. A speaker might conceivably know which type of structure a content has without knowing which structure it has. These degrees of knowledge of semantic content entail one another: knowing what the semantic content is entails knowing what its structure is, and knowing what its structure is entails knowing which type of structure it has.

My preferred way of thinking about this is in terms of three different principles. The strongest is transparency of content which entails the others.

Transparency of Content If there is a difference between the semantic contents of sentences, this is a difference detectable by the utterers of these sentences.

Transparency of structure, repeated from Sect. 2, is entailed by transparency of content.

Transparency of Structure If there is a difference in structure between the semantic contents of sentences, this is a difference detectable by the utterers of these sentences.

The weakest, in the logical sense of being entailed by the others, is transparency of structural type, or transparency of type for short.

Transparency of Type If there is a difference in structural type (i.e. between singular and nonsingular) between the semantic contents of sentences, this is a difference detectable by the utterers of these sentences.

In Sect. 4 I will argue against the stronger claims, i.e. transparency of content and of structure, and that the weakest claim, i.e. transparency of type, cannot be motivated independently of the stronger claims. I will also offer an independent argument against transparency of type, which, because of the entailment relations, will be an argument against transparency of content and of structure too.

\subsection{Discrimination and Identification}

An obvious question to ask about transparency claims, of any strength, is what exactly speakers are supposed to be able to know. Framing the principles in terms of detecting a difference suggests that only discrimination between pairs of semantic contents is required. However, the real issue is speakers' ability to identify features of individual semantic contents, in isolation. This is for two reasons.

Firstly, it is not plausible that speakers have the ability to discriminate between contents, or structures of contents, or structural types of contents without the ability to identify contents, structures, or structural types. If a speaker is indeed able to think about two utterances of sentences S1 and S2 and say that the semantic contents, P and Q, respectively are or are not identical (or have the same structure/ structural type) then the only likely explanation is that they are able to identify $\mathrm{P}$ and $\mathrm{Q}$ as both having some relevant property $\mathrm{R}$.
Secondly, even if the merely discriminatory ability were possible independently of the identificatory ability it will not be relevant in a range of cases that arise in philosophical debates. As an example consider a 'Dry Earth' scenario (Boghossian 1998; Korman 2006; Besson 2011). Oscar and Twin-Oscar utter 'Water is wet' and we, as theorists, are interested in whether it is possible that the semantic content of Oscar's sentence is a singular proposition while TwinOscar's is not despite their being internal (and narrow psychological) duplicates. The questions is whether uttering sentences with different semantic contents is compatible with being narrow psychological duplicates. There is no suggestion that either could have uttered a sentence with the other semantic content. So, what is relevant is the identificatory ability rather than the discriminatory one if any ability at all is relevant.

It is possible to imagine cases where a speaker can know some of the relevant facts without possessing the identificatory ability. Suppose that a speaker does not know the content of either S1 or S2, but they know that S1 is true (expressed a true proposition) and that $\mathrm{S} 2$ is false; perhaps they know that the utterer of S1 always says false things and the utterer of S2 always says true things. ${ }^{5}$ I assume that a version could be constructed where difference of structure is part of what the speaker can identify: suppose they know that one speaker always asserts singular propositions, and the other general. This is the right sort of case to refute the argument I have just made, except for the fact that the reason for the ability to discriminate here is not one that comes from linguistic competence. It is therefore not possible to use such cases in the way that transparency is supposed to be used. Transparency is supposed to be the claim that speakers can discriminate in all cases where they are able to be competent. Most speakers lack independent knowledge of which sentences are true (or have singular contents), and it is certainly not something that follows from linguistic competence. So, this possibility cannot be used to defend transparency if transparency is then supposed to do the work required of it in an argument like Dickie's.

\section{Against Transparency}

\subsection{Methodology}

In Sects. 4.2 and 4.3, respectively, I will present cases which tend to give rise to intuitions incompatible with the stronger forms of transparency presented in Sect. 3.1. This provides some evidence against these forms of transparency.

\footnotetext{
5 I thank an anonymous referee and Elmar Geir Unnsteinsson for versions of this case.
} 
Furthermore, the contents of these judgements can be used as premises in arguments against transparency, and the contents of these judgements are entailed by some popular, plausible views in philosophy of language and mind. I take this to be a reason to reject the two stronger forms of transparency if one either has these intuitions or has independent reasons to endorse the views that entail their contents. In Sect. 4.4 I will argue that only one or other of the two stronger forms of transparency could motivate the weakest form, and that because both stronger forms should be rejected, therefore the weakest form is unmotivated.

In Sect. 4.5 I will present another argument against all forms of transparency.

In Sect. 5 I will discuss two positive arguments for transparency and reject them.

\subsection{Transparency of Content}

Transparency of content entails that if a speaker utters a sentence which has $\mathrm{P}$ as its semantic content then the speaker knows that $\mathrm{P}$ is the content. The following examples discussed in the philosophical literature provide support for rejecting this claim. Each one involves a different linguistic construction.

- Mirror universe (pronouns) (Strawson 1959)

- Swapped pictures (demonstratives) (Kaplan 1978)

- Twin Earth (kind terms) (Putnam 1975)

- Rip Van Winkle ('automatic' indexicals) (Kaplan 1989, p. 538; Evans 1985; Perry 1996)

Mirror Universe In their respective halves of a symmetrical universe $\mathrm{John}_{\mathrm{A}}$ and $\mathrm{John}_{\mathrm{B}}$ see Mary $\mathrm{A}_{\mathrm{B}}$ sprint and utter 'She's fast' thereby expressing the proposition that Mary ${ }_{A}$ is fast or that $\mathrm{Mary}_{\mathrm{B}}$ is fast. If the Johns express singular propositions at all they include their local Mary, but they cannot discriminate between their states.

Swapped Pictures Mary points at a portrait without looking at it while uttering 'That is the greatest philosopher of the 20th century'; her portrait of Rudolf Carnap has been swapped with one of Spiro Agnew. The proposition expressed is about Spiro Agnew, not Rudolf Carnap.

Twin Earth Mary utters 'Water is wet' on Earth, where the stuff in the rivers is $\mathrm{H}_{2} \mathrm{O}$; the content expressed is the proposition that $\mathrm{H}_{2} \mathrm{O}$ is wet ( $\left\langle\right.$ wet, $\left.\left.\mathrm{H}_{2} \mathrm{O}\right\rangle\right)$. Twin Mary utters the same sentence on Twin Earth, where the stuff in the rivers is $\mathrm{XYZ}$; the content expressed is the proposition that $\mathrm{XYZ}$ is wet (〈wet, $\mathrm{XYZ}\rangle)$.

An alternative to the Twin Earth case treats different linguistic communities on Earth as equivalent in some ways to the two worlds. It is more plausible that speakers move between these communities than that they are moved between worlds (Ludlow 1995).
Deference John defers to his community about what sort of plant 'turnip' refers to. Furthermore, he moves between two communities that, unbeknownst to him, differ in this respect. ${ }^{6}$ John utters 'I would like a turnip' several times in different communities. Different propositions are expressed.

Rip Van Winkle Rip Van Winkle wakes up after twenty years asleep. He utters 'Yesterday was 3 July 1766'. The proposition expressed is about the day before his utterance, 3 July 1786, not 3 July 1766 .

These cases generate strong intuitions about content among philosophers of language. All these cases have been taken as evidence about the semantic contents of sentences. And they all suggest, in one way or another, that semantic content is not transparent. Furthermore, if the cases are as described then transparency of content is false. So, nobody can accept the intuitions prompted by any of these cases and accept transparency of content. Note that in all these cases, the change in the environment that leads to a change in content might not be detectable by the speakers involved.

Two cases in particular, mirror universe and Twin Earth, are particularly important because they have been used as motivations for whole research programmes in contemporary philosophy of language (and philosophy of mind). This is especially true of the Twin Earth case which is a key motivation for externalism about natural kind terms (Putnam 1975; Pessin and Goldberg 1996). The example of a mirror universe has been used to motivate the existence of singular contents (Strawson 1959; Evans 1982).

That the kind of externalism motivated by Twin Earth cases and their various variants raises this kind of issue for transparency is well known, see Brown (2004) for a discussion that includes a summary of the debate. Rejecting this kind of externalism is one way to go, but does not fit neatly with the project of assigning the referents of expressions as their contents and identifying the contents of sentences with structured, Russellian propositions. This gives those working in such a framework a prima facie reason to reject transparency of content.

Focusing on the Twin Earth case and its consequences for transparency brings out the connection between some of the key notions used in philosophical theories about content. In particular, the idea that referential properties of expressions are responsible for the truth conditions of sentences, and that this should be captured at some level of a theory of meaning. In the present view, these properties are captured by semantic content. This raises deep questions about the relationship between semantic content and linguistic competence: what might be pre-theoretically described as knowledge of meaning. This is what is interesting about the issue of transparency, apart from the narrow issue of how to respond to the

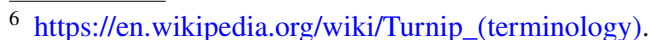


transparency intuition and its role in arguments like those Dickie makes. If reference determines truth conditions and if reference differs according to factors that are not discriminable by speakers, then linguistic competence cannot require infallible knowledge of truth conditions any more than it can require in infallible knowledge about content. We would therefore have to look for something else for linguistic competence to consist in. ${ }^{7}$

It is important to emphasise that while an externalist must accept that the content of e.g. 'water' is not transparent, it might well be that a speaker can come to correctly believe that it is $\mathrm{H}_{2} \mathrm{O}$; such a speaker may even know this. The lesson of externalism is not scepticism about content, but that knowledge of content is often partly empirical.

The point made in this section does not require rejecting the plausible claim that speakers can know that a pair of sentences have the same semantic content. For example, someone who knows that Cicero is Tully might know that a pair of sentences differing only in that an occurrence of 'Cicero' in the former is replaced by an occurrence of 'Tully' in the latter must have the same content. The point is not that speakers cannot ever know anything about content, or relations between the contents of sentences, but that linguistic competence does not require being able to identify content.

\subsection{Transparency of Structure}

My argument will require first getting clear on what propositional structure is. The question of structure in general, and propositional structure in particular, is a vexed one (Keller 2013; Gilmore 2014; Merricks 2015, chaps 4-5; Glick 2017). I am avoiding some issues by assuming that propositions are structured, and I will not offer a view about what it means for a proposition to be structured. This is a deep metaphysical question which needs to be solved, but not here. For my purposes, a rather simple notion of structure can be used which is sufficient to capture the facts about propositions that are supposed to be transparent (or not).

I will start with a definition of what it is for two propositions to have the same structure.

Same Structure Propositions P, Q have the same structure if and only if $\mathrm{P}$ and $\mathrm{Q}$ are identical in their number and

\footnotetext{
7 There is a deep debate about the role of reference, and indeed truth conditions, in semantics and in the study of meaning and linguistic behaviour. As well as the externalist tradition there has been important work developing insights of Frege $(1948,1951)$ and Dummett (1973). Chomsky has also famously rejected the idea that reference is a useful theoretical term for the study of language (Chomsky 2000); see also Stainton (2006) and King (2017). A theory of the relationship between truth conditions and meaning inspired by Chomsky is developed in Pietroski $(2003,2005)$.
}

type of constituents and in the predicational relationships between them.

By 'type of constituents' I mean that objects are one type, $n$-place properties another for all values of $n$, etc. The following propositions will have the same structure, according to this definition:

- $\langle$ dances, John $\rangle$

- 〈sings, Mary

The following pair will also have the same structure which differs from that of the first pair:

- $\langle$ loves, $\langle$ John, Mary $\rangle\rangle$

- $\langle$ loves, $\langle$ Mary, John $\rangle\rangle$

The idea of propositional structure can then be derived from equivalence classes of propositions with the same structure.

Now that it is clear how to characterise structure, I will argue against its transparency. I will use a case drawn from the literature on unarticulated constituents inspired by Perry (1986); the case itself is adapted from Recanati (2002). There is a large literature on the theoretical implications of this sort of example which I will not try to summarise (Bach 1994; Taylor 2001; Martí 2006, 2015; Borg 2005; Cappelen and Lepore 2007; Sennet 2008; Recanati 2007; Sennet 2011). I accept the conclusion of John Perry, François Recanati, and others, that there are unarticulated constituents. However, someone who rejected this would not be moved by the present argument. In that case, I will rely on the argument against all forms of transparency in Sect. 4.5.

Eating Mary utters 'John is eating'. In a suitable context the semantic content is that John is eating o where o is a salient poisonous mushroom. However, this element of content is both (i) optional and (ii) is not the semantic value of anything in the sentence uttered: it is an unarticulated constituent of semantic content.

The optionality of unarticulated constituents is required because otherwise the claim would be compatible with different propositions with the same structure being expressed in different contexts. But the claim that unarticulated constituents are optional allows for the semantic content of (1) to have the structure of either of the propositions listed below.

(1) John is eating.

- $\left\langle\right.$ eating $_{1}$, John $\rangle$

- $\left\langle\right.$ eating $_{2},\langle$ John, Mushroom $\left.\rangle\right\rangle$

Assuming unarticulated constituents, this shows that there are sentences such that they have different contents in 
different contexts and that these contents are structurally different. However, this fact in itself is not incompatible with transparency of structure because nothing so far rules out the possibility that detecting this difference is part of speakers' linguistic competence.

Someone defending transparency might now give the following argument. Whether or not sentences such as 'John is eating' or, Perry's original example, 'It is raining' have contents containing objects/locations depends on whether the speaker intended to say something about an object or location. And, this sort of intention is transparent to speakers. So, which structure the contents have is transparent to speakers.

This argument can be resisted by pointing out that it is possible to be linguistically competent and express contents containing locations without having intentions directed at those locations. Perry's case of the Z-landers can be used to illustrate this point.

Consider a small isolated group living in a place we call Z-land. Z-landers do not travel to or communicate with residents of other places, and they have no name for Z-land. When a Z-lander sees rain, he will say to others not in a position to look outdoors, 'It is raining'. His listeners then act appropriately to there being rain in Z-land: they close the windows in Z-land, cancel plans for Z-land picnics, and grab umbrellas before going into the Z-land out-of-doors (Perry 1986, p. 144).

The case shows the coherence of such a possibility: these speakers have no conception of the location of their utterances as distinct from other locations and no intentions, at least not such as are transparent to them, directed at locations. ${ }^{8}$ If this is possible, and the Z-landers are linguistically competent, then such intentions are not required for expressing a proposition with a particular structure. If the intentions are not required then their transparency does not show that the structure of content is transparent.

At most, the transparency of the relevant referential intentions shows that speakers often do know something which entails facts about the structure of content. Speakers who know that they intend to be speaking about e.g. some mushrooms could infer from this that the content they express has a particular structure. However, a speaker can be competent both if they fail to make the inference, and even if they lack the intention which they could take as a premise in such an inference.

\footnotetext{
${ }^{8}$ A parallel point could be made about the time of utterance. It has been argued by eternalists that semantic contents include these times. This would affect the structure of these contents, but speakers do not have (transparent) intentions to refer to these times (Richard 1981; Ninan 2011).
}

\subsection{Transparency of Structural Type}

Both transparency of content and transparency of structure would entail transparency of structural type. I have argued against both in Sects. 4.2 and 4.3. I will now argue that, given these conclusions, there is no motivation for transparency of structural type.

For the purposes of this paper transparency of structural type is transparency as to the difference between singular and a nonsingular content. nonsingular contents might be general, or perhaps something else e.g. gappy propositions (Braun 1993; Salmon 1998). ${ }^{9}$ I will assume that we can make sense of this distinction, perhaps along the lines of Glick (2017); my argument doesn't require any particular account of singular propositions.

As I have said, transparency of content and transparency of structure would both entail transparency of type. But, as I have argued, neither of these should be accepted. What is required to defend transparency of type is an argument that the distinction between singular and nonsingular content is special in a way that the difference is transparent in a way that other properties of content are not.

Someone might claim that the transparency of type is just obvious. But I see no reason to accept this. What would it be like to have immediate access to this property of semantic content without having such access to either content or structure? This is primarily a dialectical point: if transparency of structural type is being appealed to as part of an argument against a view that entails its negation, and if the other forms of transparency have been rejected, appealing to the intuitive obviousness of the claim will not be effective against an opponent who denies it. The result will be an impasse.

One possible response here is to identify arguments for transparency of structural type. One candidate is what I will call transparency of aboutness numerosity. The idea is that it is transparent how many things a proposition is about (on a certain metaphysical picture this amounts to it being transparent how many objects are constituents of the proposition modulo cases where propositions are about properties). If $\mathrm{i}$ is the number of objects $\mathrm{P}$ is about then $\mathrm{P}$ is singular if and only if $\mathrm{i}$ is strictly greater than zero. ${ }^{10}$

There are two reasons to reject transparency of aboutness numerosity. Firstly, cases of unarticulated constituents would be counterexamples. In these cases a speaker might believe that the proposition expressed has n constituents when in

\footnotetext{
9 Alternatively, proponents of gappy propositions might insist that they are singular; there is no need to dispute that in the present context.

${ }^{10}$ Gappy propositions as used by Braun (1993) and Salmon (1998), unless they also have objects as constituents, will complicate this if they are to be treated as singular: perhaps gaps count towards the number of objects in the proposition.
} 
fact it has $n+m$ where $m$ is the number of unarticulated constituents.

A second argument does not rely on this controversial case. Consider sentences (2), (3), and (4).

(2) Mars is Venus.

(3) Venus is Venus.

(4) Hesperus is Phosphorus.

A standard Russellian view holds that (2) has the first of the following as its content, and (3) and (4) the second.

- $\langle=,\langle$ Mars, Venus $\rangle\rangle$

- $\langle=,\langle$ Venus, Venus $\rangle\rangle$

The first of these is about two objects and the second is about one. But if this was transparent then it would be transparent that [['Hesperus']] = [['Phosphorus']]. But this is not transparent, which is why identity statements can sometimes be informative. ${ }^{11}$ I will generalise this point in Sect. 4.5.

An alternative argument would appeal to judgements about the modal profiles of various sentences. ${ }^{12}$ The idea would be that speakers make judgements about the modal profiles of sentences such as (5) and (6) which are explained the different structures of their respective contents, and speakers' access to this difference.

(5) Aristotle was fond of dogs.

(6) The teacher of Alexander the Great was fond of dogs.

The thought might be that even though speakers might not be able to identify the specific contents, the transparency of type is what explains their judgements about modal profile; they know that whatever the contents are, they are of different types with distinct properties.

This, the argument from modal profile, like the argument from aboutness numerosity, is of the right form to establish transparency of structural type. However, the argument is only as good as the claim that not only do (5) and (6) have semantic contents of different types, but speakers make judgements that that fact would explain. One challenge for this argument would be to point out the seeming variability

\footnotetext{
11 Some theories of propositions will complicate this point. For example, Kit Fine defends a view according to which some propositions have 'links' between constituents which reflect de jure coreference relations between terms in the sentences that express them (Fine 2007). If that view is assumed, it is plausible that facts about linking are transparent. So, something like transparency of aboutness numerosity holds in some cases. But this would not be a general defence of transparency. I thank Elmar Geir Unnsteinsson for discussion of this point.

${ }^{12}$ I thank an anonymous referee for suggesting this response.
}

of the intuitions here. For example, the point about modal profile was argued for by Saul Kripke, and a related point was made earlier, but in a more formal context, by Marcus (1961) and Kripke (1980). ${ }^{13}$ The difference, even if we accept it, was not just obvious to the people that Kripke was arguing against, including Russell (1905). If the judgements are not universal then there is no need to posit transparency of structural type to explain them. As I will discuss in Sect. 4.5, the key point once again is that transparency of structural type would make it too easy to resolve certain disputes in philosophy of language which are in fact difficult.

I take this to be a dilemma for the defender of transparency of type. On the first horn, transparency of type is supposed to follow from the transparency of something else. But there are no good candidates for what this would be. I have considered and rejected content, structure, referential intentions, and numerosity of aboutness in the preceding discussion. On the second horn, it is something special about the singular nonsingular distinction itself. It just is transparent. But without an explanation of why this is so, this just amounts to repeating the transparency intuition. This is not helpful in the context of the debates in which transparency of structural type is appealed to, such as the paper of Dickie's I referred to in Sect. 2.

A possible response here is to claim that transparency of structural type is a methodological principle. ${ }^{14}$ More precisely, it is supposed to a methodological principle that the semantic type of expressions is transparent. And this is supposed to entail, via the claim that the semantic type determines the structural type of the content, that structural type is transparent. I concede that this is compatible with the arguments of this paper so far. So, if someone thinks that this is a methodological principle I have given them no reason to change their mind. In Sect. 4.5 I will give an argument that should convince them. In any case, I see no compelling motivation for the principle; there is nothing that it allows us to explain that could not otherwise be explained.

\subsection{Easy Knowledge}

I will now give a different argument against transparency that targets all the degrees of strength discussed in Sects. 4.2, 4.3, and 4.4. The argument builds on the argument against transparency of aboutness numerosity in Sect. 4.4.

Transparency, of any strength, would entail that speakers are in a position to know things about semantic content that

\footnotetext{
13 There is also a recent related debate about the cross-cultural variability of intuitions. Machery et al. (2004) and Mallon et al. (2009) develop these into arguments against the Kripkean view; Ichikawa et al. (2012) responds.

${ }^{14}$ I thank an anonymous referee for suggesting this; they suggest that the view can be attributed to Kripke (2013, p. 30).
} 
they are not in fact in a position to know. More precisely, speakers are not in a position to know these things through the kind of introspection that transparency would allow them to make use of. I will illustrate this point with debates from philosophy of language. I could have used at least one more example: the view about empty names that Dickie is discussing in the passage quoted in Sect. 2. However, I don't want to make claims about this case as part of the argument against transparency because my interest in transparency is in the way it can contribute to the debate over empty names.

The first example is quantifier domain restriction. The key datum is not particularly controversial. Most theorists agree that an utterance of (7) is typically used to say e.g. that every bottle of beer in the house is empty.

\section{(7) Every bottle is empty.}

But there has been a significant dispute over what the semantic content of (7) is, and how that interacts with what is said. In particular, there is a dispute over whether the semantic content is a proposition true if and only if every bottle (punkt) is empty, or one that is true if and only if every bottle of beer in the house is empty. The latter view might be combined with the view that the syntactic structure of the sentence is richer than it appears. The former view would be combined with an account of how the sentence with one semantic content can be used to say the more specific proposition. For this debate see e.g. Stanley and Szabó (2000); Stanley and Szabó defend the view that the domain restriction is effected by a covert variable present in syntax. As Stanley and Szabó (2000, p. 240) note, Kent Bach is the philosopher most associated with the pragmatic view, see Bach (1994, 1997).

This debate proceeds by subtle theorising that aims to balance intuitions about what is said with the best theories we have about syntactic structure. This debate would be wholly misguided if competent speakers had direct access to semantic content. Given that the debate does not seem to be misguided, this is evidence that competent speakers do not have this direct access.

The quantifier domain restriction case counts against transparency of content, but not against transparency of structure. Two other examples play this role. The first example is the semantic content of sentences containing definite descriptions such as (8).

(8) The largest university in South America is in Mexico.

According to the classic analysis of Russell (1905) the semantic content of $(8)$ is general i.e. it has a structure reflecting the logical form $\exists x(F x \wedge \forall y(F y \rightarrow x=y) \wedge G x)$ (Ludlow 2013). This claim has been much debated (Neale
1990). ${ }^{15}$ Whatever one thinks about the analysis, this is not something to be decided by introspection.

Another case is that of complex demonstratives. The debate is over whether sentences such as (9) express singular or general propositions (King 2001, 2008; Braun 2008). ${ }^{16}$

\section{(9) That big dog is friendly.}

This debate could be resolved if Sect. 4.4 is true. But, like the other cases, this would make it easier than it in fact is to get knowledge about semantic content.

Related to all the above examples is another point against transparency. Philosophers of language and linguists generally agree that it is easy for speakers to confuse semantic content with what is said. This is a very widely discussed phenomenon, see e.g. Salmon (1991); Borg (2004); Cappelen and Lepore (2005). But, if semantic content is transparent this would be very hard to do. Instead, it seems as if competent speakers in ordinary conditions find it quite easy to identify what is said. But, they often simply do not consider semantic content and when they do they tend to make judgements that conflict with the best theories about semantic content.

There are two related issues here. The first is that we just do not access semantic content through introspection, which we could if it was transparent. From this we can conclude that it is not transparent. The second point is that discovering semantic content is hard, whereas it would be easy if it was transparent. From this we can also conclude that it is not transparent. The claim that accessing content is hard can be used to argue that we do not access the content through introspection, because introspection would be easy. The two points taken together offer an explanation for the fact that identifying semantic content is hard.

I conclude from these examples that no form of transparency can be reconciled with the way that philosophy of language and linguistics actually proceeds. In general, both speakers and theorists proceed to knowledge of semantic content, when they have it, by a mixture of empirical and theoretical considerations. The empirical considerations are more relevant when the content of simple expressions, e.g. 'water', is under consideration, and theoretical considerations are more relevant to judgements about the structure of content. It is harder to get knowledge about semantic content

\footnotetext{
15 Neale (1990) defended the view that sentences such as (8) are semantically nonsingular i.e. Russellian and sometimes convey singular contents. The point is not who is right, but that the dispute is conducted by appealing to a range of linguistic data and philosophical arguments. Not introspection. Neale (2005) surveys a range of responses to Russell (1905).

16 There are more than two sorts of proposal, of course, see Neale (1999) and Dever (2001).
} 
than would be the case if any form of transparency held, and when we do have it, we do not get it from introspection.

This concludes my arguments against transparency in its various forms. In Sect. 5 I will strengthen my case by responding to two promising arguments for transparency.

\section{For Transparency}

\subsection{Truth Conditional Semantics}

One reason that might be offered for transparency of content is that, as part of being competent, speakers know the truth conditions of the sentences they utter. That knowledge of truth conditions is a key part of linguistic competence is at least one motivation for the project of truth conditional semantics, and that project might appear weakened with this claim. ${ }^{17}$ And, truth conditions are determined by semantic content; a sentence is true just in case its semantic content is. So, the argument goes, truth conditions are transparent and this is explained by what grounds truth conditions, semantic content, being transparent.

The first line of response is to point out that competent speakers are not infallible about truth conditions. At best they are reliable. This can be brought out with both externalist cases, e.g. slow switched speakers who do not realise that the content of 'water' is now XYZ, and ordinary examples of error. Another source of more philosophical examples can be found in the literature on semantic error (Rysiew 2016, Sect. 4.3).

I will first consider an argument for transparency I take to be valid but unsound. It is unsound because it has the claims about infallibility as a premise. I will then consider a sound argument with a weaker conclusion compatible with the denial of transparency. I will argue that this conclusion captures what we ought to say about knowledge of truth conditions.

Before presenting the unsound argument I will clarify the use to which I am putting it. I am not claiming that anybody has actually defended transparency in this way. My point is that this argument, which is bad, would be the way to connect a premise about truth conditions with the conclusion that semantic content is transparent. An argument with a weaker premise would not be valid. I conclude from this that an argument based on speakers' infallibility about truth conditions cannot be used to establish transparency of content.

1. Speakers are infallible about truth conditions.

2. Truth conditions are fixed by semantic content.

\footnotetext{
17 For introductions to truth conditional semantics see Larson and Segal (1995) and Heim and Kratzer (1997).
}

3. Speakers are infallible about semantic content (from 1 and 2).

4. Semantic content is transparent (from 3).

Premise 1 is false; speakers make mistakes about truth conditions all the time. For example, they confuse them with the contribution of pragmatics. In other words, speakers very often confuse the semantic content of a sentence with e.g. what a speaker intended to convey by their utterance of that sentence. Alternatively, some philosophers and linguists such as Recanati and relevance theorists, hold that pragmatic factors affect 'literal' truth conditional content (Sperber and Wilson 1995; Carston 2002; Recanati 2004). This will not be a problem for my argument, because, on an alternative description where truth conditions include these pragmatic factors, premise 2 is false.

Something weaker than premise 1 is more plausible. Perhaps, under relatively ideal conditions, speakers are reliable about semantic content. Relatively ideal conditions will include both adverse conditions leading to performance errors, and also to hard cases where the contribution of a pragmatic mechanism is not obvious.

The kind of reliability I have in mind is the kind of reliability that leads to speakers avoiding gross errors. For example, no ordinary, competent speaker under anything like ideal conditions will judge that (10) is true if and only if John dances. ${ }^{18}$

\section{(10) Mary sings.}

Being competent with (10) requires knowing this fact about (10). Avoiding gross errors does not entail avoiding subtle errors. Avoiding even subtle errors is a necessary condition for infallibility but not for reliability.

This point helps the opponent of transparency answer at least one sort of objection. If speaker judgements are reliable then they can be data for linguistic and philosophical theorising about language. Denying transparency does not, therefore, have a particularly high epistemic cost.

Someone might object at this point that it will be unclear why speakers are reliable if they are not infallible, and infallible because content is transparent. I agree that this is a philosophical puzzle: there is a tension between the claim that speakers have justified beliefs about semantic facts and the claim that these facts vary with the environment in undetectable ways. This is a deep problem that motivates much of the debate over externalism, and has also been discussed in

\footnotetext{
18 The ordinary conditions here are supposed to rule out cases where the speaker believes, even truly, that 'Mary sings' and 'John dances' are extensionally equivalent; the knowledge in question is that they have different truth conditions.
} 
recent work on metasemantics (Kearns and Magidor 2012; Dorr and Hawthorne 2014).

I think it is possible to deal with some of the worries by pointing out what a speaker can know about a sentence such as (10) without knowing which proposition is its content. Firstly, they might know that a sentence with the structure of (10) is true if and only if the object denoted by the NP is in the extension of the property denoted by the VP i.e. [['sings']] ([['Mary']]) = 1 (assuming that the semantic values of NPs are of type e and VPs are of type et in a system such as that described in Heim and Kratzer (1997)). ${ }^{19}$ This does not require knowledge of what the propositional semantic content of (10) is.

Combined with information about what [['sings']] and [['Mary']] are a speaker may get more information about what the truth conditions of (10) are. ${ }^{20}$ Acquiring this additional information might lead someone to the conclusion that the semantic content of (10) is 〈sings, Mary〉; this will require inference and philosophical work rather than simple transparency of content. Rejecting transparency does not require rejecting that speakers often do know the facts that let them infer the contents of the sentences that they utter. And, if they can often infer the contents, they can infer the truth conditions.

The point in the preceding paragraph is intended to support the reliability of speakers about truth conditions. It also suggests a second sort of response that can be made to the general worry that is at issue in this section. Even if speakers lack knowledge of the semantic values of constituents of sentences, they might know something at a more general level about sentences such as (10). For example, they might know what types of constituents sentences like that have, and how they combine. This allows them to know something about the truth conditions that sentences will have given various semantic values for their constituents.

The points made in the previous paragraphs fit with the claim about intentions made in Sect. 4.3. If having intentions of a certain sort is sufficient for expressing a content with a certain structure, and if those intentions are transparent, then speakers might know a lot about content in ordinary cases. That is why they are reliable about content, and therefore about truth conditions.

\footnotetext{
${ }_{19}$ I depart from Irene Heim and Angelika Kratzer's notation by using single quotes to indicate mention.

20 There are interesting questions here about the cognitive psychology of utterance processing and knowledge of content which go well beyond the scope of this paper. However, this picture is compatible with the view that part of utterance processing is the assignment of meanings to sentences in context by an encapsulated, and internally specifiable module similar to the syntax module posited by many linguists. This output may then be combined with world knowledge to arrive at beliefs about what I have called semantic content. A view of this sort is defended by Borg $(2004,2012)$.
}

The two responses are different because the first response argues that speakers might be reliable about content and therefore about truth conditions even if they are not infallible. The second response complements the first because it argues that while speakers may not always have knowledge of content, they may still know various informative things about the semantic properties of sentences. And this tacit knowledge is sufficient for ordinary linguistic competence.

This suggests a way to think about linguistic competence, or rather linguistic competences, that is independently attractive. The idea would be that speakers have (tacit) knowledge of syntactic structure in a roughly Chomskian way. And, speakers have a degree of tacit semantic knowledge which takes the form of conditional claims about what the content of various expressions would be in various circumstances. This is combined with semantic knowledge about how contents combine. And, it is combined with knowledge of reference. This results in a situation where speakers have a range of beliefs about the contents of sentences and they are often right.

Because the world might not be cooperative, and because speakers are prone to confuse semantic content and what is said, many highly competent speakers have false beliefs about the contents of particular sentences on particular occasions. This leads to false beliefs about truth conditions. This general picture, I claim, is the best that we currently have about the nature of linguistic competence and its connection to content.

This picture is a good fit for what some formal semanticists are actually doing: they are concerned with investigating how constituents can be assigned values of various types and how these types combine rather than with the values assigned to particular expressions. For example, the denotation of 'water' is not as important as its type for the purpose of truth conditional semantics as it is currently practised. ${ }^{21}$

\subsection{Syntactic Structure is Transparent}

Another argument that might motivate transparency is based on the idea that speakers know the syntactic structure of the sentences they utter, and that this structure determines the structure of semantic content. The claim that part of linguistic competence is tacit knowledge of syntactic structure is a central claim of Chomskian linguistics (Dwyer and Pietroski 1996). This argument would not be a reason to accept transparency of content, but it would be a reason to accept transparency of structure.

The argument might be represented like this:

\footnotetext{
${ }^{21}$ I heard Barbara Partee make a related point in response to a talk by Stephen Schiffer which was later published as Schiffer (2015).
} 
1. Syntactic structure is transparent.

2. Syntactic structure determines the structure of semantic content.

3. So, the structure of semantic content is transparent.

One obvious objection to this argument is that standard views about tacit syntactic knowledge do not entail that syntactic structure is transparent. One good reason to reject this strong version of syntactic knowledge is parallel to the worries raised for a similar view about content in Sect. 4.5. The problem would be that discovering the structure of sentences is a difficult and subtle task and disputes are not settled by appeal to introspection. What speakers seem to have is reliable, but not infallible, judgements about acceptability. ${ }^{22}$ If this is so, the tacit knowledge of syntax posited by Chomskian linguists would not be equivalent to transparency of syntactic structure in the sense required for premise 1. I will not rely on this point, however, because in any case premise 2 is false and the reasons for this are both clearer and more properly philosophical.

Premise 2 is sometimes asserted by defenders of Russellian views, or is entailed by their views but not explicitly endorsed. Jeffrey C. King explicitly endorses it (King 2007; King et al. 2014). The first reason to reject premise 2 is that, combined with premise 1 , this view would lead to the problems raised in Sect. 4.5. It would be possible to use knowledge of syntactic structure to get knowledge of propositional structure and therefore resolve e.g. the question of whether sentences containing complex demonstratives have singular contents. This is a reason to reject premise 2, at least if premise 1 is true. If premise 1 is not true, then, even if premise 2 is, the argument for transparency will not go through.

\section{Conclusion}

In Sects. 2 and 3 I identified a question: is semantic content transparent. In Sect. 4 I answered that question negatively. In Sect. 5 I responded to arguments for a positive answer; this supports my negative answer.

These arguments help us to better understand the nature of semantic content and the access that linguistic agents have to it. I will explore the consequences of these arguments for other core issues in the philosophy of language, such as the problem of empty names, in future work.

Acknowledgements I thank Corine Besson, Robert Elstein, Giulia Felappi, Geoff Georgi, Jumbly Grindrod, Minyao Huang, Dirk Kindermann, Genoveva Martí, Matthew McKeever, Joey Pollock, Robert Trueman, and Elmar Geir Unnsteinsson, two anonymous referees, and

${ }^{22}$ For a discussion of the methodological issues here see Phillips (2009) and Ludlow (2011). audiences at the Context Dependence in Language, Action and Cognition conference at the University of Warsaw and the 2016 Joint Session of the Aristotelian Society and the Mind Association. This research was supported by an Irish Research Council Government of Ireland Postdoctoral Fellowship.

Open Access This article is distributed under the terms of the Creative Commons Attribution 4.0 International License (http://creativecommons.org/licenses/by/4.0/), which permits unrestricted use, distribution, and reproduction in any medium, provided you give appropriate credit to the original author(s) and the source, provide a link to the Creative Commons license, and indicate if changes were made.

\section{References}

Bach K (1994) Conversational impliciture. Mind Lang 9(2):124-162. https://doi.org/10.1111/j.1468-0017.1994.tb00220.x

Bach K (1997) The semantics-pragmatics distinction: what it is and why it matters. In: Rolf E (ed) Pragmatik. Linguistische Berichte (Forschung Information Diskussion). VS Verlag für Sozialwissenschaften, Wiesbaden, pp 33-50. http://link.springer.com/ chapter/10.1007/978-3-663-11116-0_3. Visited 12 October 2016

Besson C (2011) Empty natural kind terms and Dry-Earth. Erkenntnis 76(3):403-425. https://doi.org/10.1007/s10670-011-9286-y

Boghossian PA (1998) What the externalist can know a priori. Philos Issues 9:197-211. https://doi.org/10.2307/1522971

Borg E (2004) Minimal semantics. Oxford University Press, Oxford

Borg E (2005) Saying what you mean: unarticulated constituents and communication. In: Ellipsis and nonsentential speech. Studies in linguistics and philosophy, vol 81. Springer, Dordrecht, pp 237-262. https://link.springer.com/chapter/10.1007/1-4020-2301-4_13. Visited 22 September 2017

Borg E (2012) Pursuing meaning. Oxford University Press, Oxford

Braun D (1993) Empty names. Noûs 27(4):449-469. https://doi. org/10.2307/2215787

Braun D (2008) Complex demonstratives and their singular contents. Linguist Philos 31(1):57-99. https://doi.org/10.1007/ s10988-008-9032-3

Brown J (2004) Anti-individualism and knowledge. MIT Press, Cambridge

Cappelen H, Lepore E (2005) Insensitive semantics: a defense of semantic minimalism and speech act pluralism. Wiley-Blackwell, Oxford

Cappelen H, Lepore E (2007) The myth of unarticulated constituents. In: O'Rourke M, Washington C (eds) Situating semantics: essays on the philosophy of John Perry. MIT Press, Cambridge, pp 199-214

Carston R (2002) Thoughts and utterances: the pragmatics of explicit communication. Blackwell, Oxford

Chomsky N (2000) New horizons in the study of language and mind. Cambridge University Press, Cambridge

Dever J (2001) Complex demonstratives. Linguist Philos 24(3):271330. https://doi.org/10.1023/A:1010730709736

Dickie I (2014) A practical solution to the problem of empty singular thought. In: García-Carpintero M, Martí G (eds) Empty representations: reference and non-existence. Oxford University Press, Oxford, pp 215-242

Dorr C, Hawthorne J (2014) Semantic plasticity and speech reports. Philos Rev 123(3):281-338. https://doi. org/10.1215/00318108-2683531

Dummett M (1973) Frege: philosophy of language. Duckworth, London 
Dwyer S, Pietroski PM (1996) Believing in language. Philos Sci 63(3):338-373. https://doi.org/10.1086/289916

Evans G (1982) In: McDowell J (ed) The varieties of reference. Oxford University Press, Oxford

Evans G (1985) Understanding demonstratives. In: Phillips A (ed) Collected papers. Oxford University Press, Oxford, pp 280-304

Fine K (2007) Semantic relationism. Wiley, London

Frege G (1948) Sense and reference (trans Black M). Philos Rev 57(3):209-230. https://doi.org/10.2307/2181485

Frege G (1951) On concept and object (trans Geach PT, Black M). Mind 60(238):168-180. https://doi.org/10.1093/mind/ LX.238.168

Gilmore C (2014) Parts of propositions. In: Kleinschmidt S (ed) Mereology and location. Oxford University Press, Oxford, pp 156-208

Glick EN (2017) What is a singular proposition? Mind. https://doi. org/10.1093/mind/fzw063. Visited 25 July 2017

Heim I, Kratzer A (1997) Semantics in generative grammar. Wiley, Oxford

Ichikawa J, Maitra I, Weatherson B (2012) In defense of a Kripkean dogma. Philos Phenomenol Res 85(1):56-68. https://doi. org/10.1111/j.1933-1592.2010.00478.x

Kaplan D (1978) Dthat. In: Cole P (ed) Pragmatics, vol 9. Syntax and semantics. Academic Press, New York, pp 221-243

Kaplan D (1989) Demonstratives. In: Almog J, Perry J, Wettstein H (eds) Themes from Kaplan. Oxford University Press, Oxford, pp 481-563

Kearns S, Magidor O (2012) Semantic sovereignty. Philos Phenomenol Res 85(2):322-350. https://doi. org/10.1111/j.1933-1592.2012.00624.x

Keller LJ (2013) The metaphysics of propositional constituency. Can J Philos 43(5):655-678. https://doi.org/10.1080/00455091.2013 .870735

King JC (2001) Complex demonstratives: a quantificational account. MIT Press, Cambridge

King JC (2007) The nature and structure of content. Oxford University Press, Oxford

King JC (2008) Complex demonstratives, QI uses, and direct reference. Philos Rev 117(1):99-117. https://doi. org/10.1215/00318108-2007-026

King JC (2017) W(h)ither semantics!(?) Noûs. https://doi.org/10.1111/ nous. 12195

King JC, Soames S, Speaks J (2014) New thinking about propositions. Oxford University Press, Oxford

Korman DZ (2006) What externalists should say about Dry Earth. J Philos 103(10):503-520. https://doi.org/10.5840/ jphil20061031030

Kripke SA (1980) Naming and necessity. Harvard University Press, Cambridge

Kripke SA (2013) Reference and existence: the John Locke lectures. Oxford University Press, Oxford

Larson R, Segal G (1995) Knowledge of meaning: an introduction to semantic theory. MIT Press, Cambridge

Ludlow P (1995) Externalism, self-knowledge, and the prevalence of slow switching. Analysis 55(1):45-49. https://doi. org/10.2307/3328619

Ludlow P (2011) The philosophy of generative linguistics. Oxford University Press, Oxford

Ludlow P (2013) Descriptions. In: Zalta EN (ed) The Stanford encyclopedia of philosophy. Fall 2013. Metaphysics Research Lab, Stanford University. https://plato.stanford.edu/archives/fall2013/ entries/descriptions/. Visited 5 June 2017

Machery E et al (2004) Semantics, cross-cultural style. Cognition 92(3):B1-B12. https://doi.org/10.1016/j.cognition.2003.10.003

Mallon R et al (2009) Against arguments from reference. Philos Phenomenol Res 79(2):332-356. https://doi. org/10.1111/j.1933-1592.2009.00281.x
Marcus RB (1961) Modalities and intensional languages. Synthese 13(4):303-322. https://doi.org/10.1007/BF00486629

Martí L (2006) Unarticulated constituents revisited. Linguist Philos 29(2):135-166. https://doi.org/10.1007/s10988-005-4740-4

Martí L (2015) Grammar versus pragmatics: carving nature at the joints. Mind Lang 30(4):437-473. https://doi.org/10.1111/ mila. 12086

Merricks T (2015) Propositions. Oxford University Press, Oxford

Neale S (1990) Descriptions. MIT Press, Cambridge

Neale S (1999) Coloring and composition. In: Murasugi K, Stainton RJ (eds) Philosophy and linguistics. Westview Press, Boulder, pp 35-82

Neale S (2005) A century later. Mind 114(456):809-871. https://doi. org/10.1093/mind/fzi809

Ninan D (2011) Semantics and the objects of assertion. Linguist Philos 33(5):355-380. https://doi.org/10.1007/ s10988-011-9084-7

Perry J (1986) Thought without representation. In: Proceedings of the Aristotelian Society, vol 60, pp 137-151. https://doi. org/10.1093/aristoteliansupp/60.1.137

Perry J (1996) Rip Van Winkle and other characters. Eur Rev Philos 2:13-39 https://web.stanford.edu/group/cslipublications/cslipublications/site/1575860724.shtml

Pessin A, Goldberg S (1996) The Twin Earth chronicles: twenty years of reflection on Hilary Putnam's "The meaning of 'meaning'". M. E. Sharpe, Armonk

Phillips C (2009) Should we impeach armchair linguists? In: Iwasaki $\mathrm{S}$ et al (eds) Proceedings from Japanese/Korean linguistics

Pietroski PM (2003) The character of natural language semantics. In: Barber A (ed) Epistemology of language. Oxford University Press, Oxford, pp 217-256

Pietroski PM (2005) Meaning before truth. In: Preyer G, Peter G (eds) Contextualism in philosophy: knowledge, meaning, and truth. Oxford University Press, Oxford, pp 255-302

Putnam H (1975) The meaning of meaning. Minn Stud Philos Sci $7: 131-193$

Recanati F (2002) Unarticulated constituents. Linguist Philos 25(3):299-345. https://doi.org/10.1023/A:1015267930510

Recanati F (2004) Literal meaning. Cambridge University Press, Cambridge

Recanati F (2007) It is raining (somewhere). Linguist Philos 30(1):123-146. https://doi.org/10.1007/s10988-006-9007-1

Richard M (1981) Temporalism and eternalism. Philos Stud 39(1):113. https://doi.org/10.1007/BF00354808. Visited 26 March 2016

Russell B (1903) The principles of mathematics, vol 1. Cambridge University Press, Cambridge. http://people.umass.edu/klement/ pom/

Russell B (1905) On denoting. Mind 14(4):479-493. https://doi. org/10.1093/mind/XIV.4.479

Rysiew P (2016) Epistemic contextualism. In: Zalta EN (ed) The Stanford encyclopedia of philosophy. Winter 2016. Metaphysics Research Lab, Stanford University. https://plato.stanford.edu/ archives/win2016/entries/contextualism-epistemology/

Salmon N (1991) The pragmatic fallacy. Philos Stud 63(1):83-97. https://doi.org/10.1007/BF00375998

Salmon N (1998) Nonexistence. Noûs 32(3):277-319. https://doi. org/10.1111/0029-4624.00101

Schiffer S (2015) Meaning and formal semantics in generative grammar. Erkenntnis 80:61-87. https://doi.org/10.1007/ s10670-014-9660-7

Schroeter L (2007) The illusion of transparency. Australas J Philos 85(4):597-618. https://doi.org/10.1080/00048400701654820

Sennet A (2008) The binding argument and pragmatic enrichment, or, why philosophers care even more than weathermen about 'raining'. Philos Compass 3(1):135-157. https://doi. org/10.1111/j.1747-9991.2007.00103.x 
Sennet A (2011) Unarticulated constituents and propositional structure. Mind Lang 26(4):412-435. https://doi. org/10.1111/j.1468-0017.2011.01423.x

Sperber D, Wilson D (1995) Relevance: communication and cognition, 2nd edn. Blackwell, Oxford

Stainton RJ (2006) Meaning and reference: some Chomskian themes. In: Lepore E, Smith BC (eds) The Oxford handbook of philosophy of language. Oxford University Press, Oxford, pp 913-940
Stanley J, Szabó ZG (2000) On quantifier domain restriction. Mind Lang 15(2):219-261. https://doi.org/10.1111/1468-0017.00130

Strawson PF (1959) Individuals: an essay in descriptive metaphysics. Methuen, London

Taylor KA (2001) Sex, breakfast, and descriptus interruptus. Synthese 128(1):45-61. https://doi.org/10.1023/A:1010349621943 